\title{
BI-GELS: A NOVEL MATERIAL FOR TRANSDERMAL DRUG DELIVERY
}

\author{
SARIPILLI RAJESWARI*, RAJESWARI PULLABHATLA, CHUKKA YERNI SATYAVATHI
}

Department of Pharmaceutical Technology, Maharajah's College of Pharmacy, Vizianagaram, Andhra Pradesh, India. Email: rajeswarimalli@gmail.com

Received: 1 January 2021, Revised and Accepted: 15 February 2021

\section{ABSTRACT}

Bi-gels semi solid formulation is combination of organogel and hydrogel with better application property such as pharmaceutical and cosmetics. The main objective of this review is specially focuses on application of bi-gels as drug delivery vehicles by transdermal route. It contains two different phases which are polar and nonpolar due to which, it possess some significant features such as ability to deliver the hydrophilic and hydrophobic drugs which also have improved permeability of drugs, better spreading ability, and water wash ability. Hence, bigels have both organogels and hydrogels they can enhanced hydration of stratum corneum and also had an ability to manipulate the drug release rate from the dosage from.

Keywords: Bi-gels, Hydrogels, Organogels, Transdermal drug delivery.

(C) 2021 The Authors. Published by Innovare Academic Sciences Pvt Ltd. This is an open access article under the CC BY license (http://creativecommons.org/ licenses/by/4.0/) DOI: http://dx.doi.org/10.22159/ijs.2021v9i2.40674. Journal homepage: https://innovareacademics.in/journals/index.php/ijs

\section{INTRODUCTION}

Due to high patient compliance, topical drug delivery is one of the commonly used drug delivery system. The formulation is applied over the skin, where skin is one of the largest organs in the body. Skin has several functions in the body which includes protection from microbes, thermoregulation, physical stress, and even from harmful radiation such as UV rays from sunlight. It has got good patient compliance when compared to other conventional method due to the following reason such as easiness of application, painless application, does not required trained medical staff for administration, helps in avoiding first pass metabolism, and can be applied to all types of patient regardless of age. Such merits made this particular route of administration one of the best in medical field.

Gels are semisolid formulation which is composed of two phases contain solid and liquid [1]. Solid phase contain gelling agent/gellator and liquid phase contain solvent. On the basis of polarity of the solvents gels are categories into different types organogel (Nonpolar solvent), hydrogel (Polar solvent)

Some new gels have also been reported such as emulgels and bi-gels [2]. They have good water content present in their structure providing hydration of stratum corneum. The hydrogel present in the bigel helps in proper hydration of stratum corneum, and the organogel present in the bigel helps in increased penetration.

Bi-gels are quite new as compared to other gels formulations. These are uniform semisolid dispersion system which contains that two gel phases are mixed together with the help of high shear rate and appear to visually seen as single gel phase [3].

\section{ADVANTAGES OF BIGELS OVER ORGANOGELS AND HYDROGELS [4,5]}

1. Improved stability.

2. Imparts wash ability.

3. Good patient compliance without compromising the beneficial effects of the oil.

4. They are easy to prepare.

5. Less amount of surfactant, less toxic.

6. They can accommodate both the hydrophilic and lipophilic drugs due to the presence of two phases.

7. It can easily penetrate through the skin. Hence, it is better choice for transdermal drug delivery.

8. Bi-gels are capable to regulating the delivery of active substances.

9. It is suitable carrier for iontophoretic drug delivery

\section{DISADVANTAGES}

1. Phase separation in the absence of emulsifier.

2. Bi-gels are unstable at higher temperatures and thermo-irreversible.

\section{TYPES OF BIGELS [6-10]}

Bi-gels preparation are classified into four categories (Fig. 1).

Oleogel dispersed in hydrogel system $(0 / \mathrm{W})$

This type of bi-gels contains oleogel as dispersed phase within the hydrogel as continuous phase.

\section{Hydrogel dispered in oleo gel (W/0)}

This type of bi-gels contains hydrogel as dispersed phase with in the oleogel as continuous phase.

\section{Bicontinuous bi-gel}

These bi-gel are formed when the gel formation is carried out at higher proportion of hydrogel/oleogel dispersed in lower proportion of oleogel/hydrogel phase, respectively.

\section{Complex bi-gel}

These bi-gels are prepared by adding organogel/hydrogel to an oil-inwater/water-in-oil structured emulsion.

\section{METHOD OF PREPARATION OF BI-GELS}

\section{Preparation of hydrogel}

Hydrogel is aqueous dispersion phase containing three dimensional network. Three dimensional network formed by either natural or synthetic gelling agent such as hydrogelator to immobilize the aqueous phase [11]. Important process parameters, such as shear speed and temperature, should be optimized based on the gelling behavior of the system [12]. The physical hydrogels are reversible in nature and gellation is attributed to some interaction such as Van der Waals force and hydrogen bonding. Chemical hydrogels are also called as permanent gels which are formed through covalent bonding results in the formation of cross-linked network [13] and schematic diagram of preparation of hydrogels (Fig. 2). 
Preparation of oleogel

Oleogel is organogel phase usually made by self-assembly of either polymer or low molecular weight components to entrap the aqueous phase [14-17]. Accurately weighed quantity of organogelator such as fatty acids, fatty alcohol, lecithin, waxes, cyclodextrins steroids, and its derivatives, in predefined oil phase at a constant homogenization condition and temperature higher than melting point of the organogelator. The gellation will be formed when the temperature is brought down to room temperature $25^{\circ} \mathrm{C}$ [18-24].

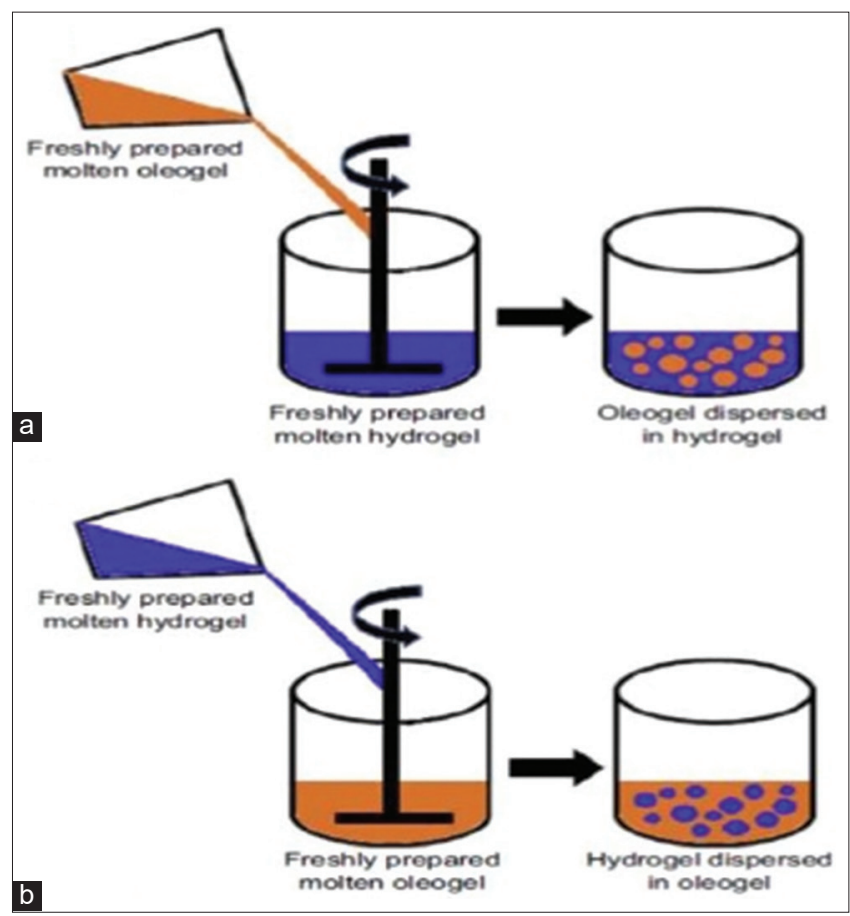

Fig. 1: Schematic diagram representing the formation of different types of bi-gels (a) oleogel dispersed in hydrogel and (b) hydrogel dispersed in oleoge

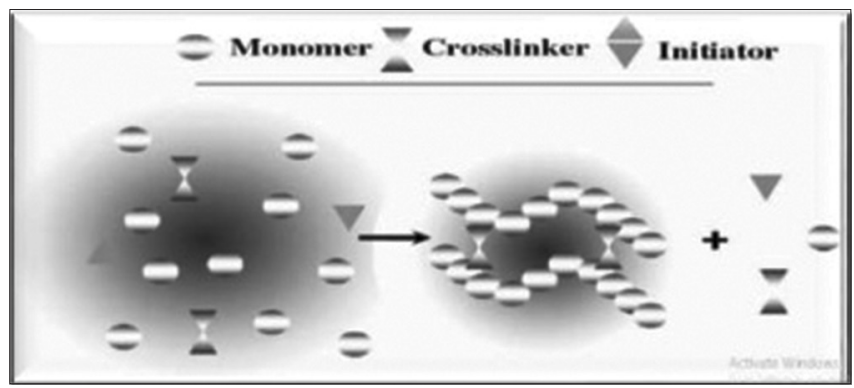

Fig. 2: Schematic diagram of preparation of hydrogel
Preparation of bi-gel

Bi-gel is prepared by mixing of hydrogel and oleogel at high shear rate without alter the characteristic properties of the both component. The homogenous mixture forms a smooth gel at particular shear speed and temperature. The stable bi-gel formation mainly depends on the composition of both the phases. Finally, gel formation checked by the tube inversion test method [25] and schematic diagram of preparation of hydrogels (Fig. 3).

\section{CHARACTERISTICS}

Bi-gels are characterized for physical, mechanical, structural, thermal, rheological, and electrical properties for their utilization in different commercial applications [26].

The mechanical properties are affected by several parameters such as oleogel/hydrogel content, polymer structure (linear or branched), and concentration of polymer. The increasing in concentration of oleogel leads to stiffness, cohesiveness, viscosity, firmness, adhesives and creep recovery of bi-gels [27]. Likewise increasing the concentration of hydrogel content leads to increase in hardness was observed. Bi-gels containing branched structured polymer as water structuring agent show higher gel strength and better resistance than liner structure polymer, but it had poor stress relaxation [28]. The water structuring agent shown profound effect such as firmness, stickiness, spread ability, stickiness, stress relaxation, and residual stress of the bi-gel system [29].

Structural properties also major factor of bi-gel stability. The structural distribution of each phase within the system and droplet size in the dispersed phase can be easily estimated by the microscopic analysis [27].

Physical properties are easily estimated after preparation of bi-gel cool down at room temperature and subjected to analysis of appearance, color, homogeneity, consistency, etc. In general, bi-gels are in white to off-white in color and viscous in nature.

Thermal properties also an important attributes of bi-gel stability for their successful commercial utilization. Thermal stability of bigels enhanced by increasing the oleogel phase or organo gelator concentration $[6,30,31]$. Thermal properties of the bi-gel are studied using the differential scanning calorimetry performed under inert $\mathrm{N}_{2}$ gas atmosphere using aluminium crucible with pierced aluminum lid. Fifteen milligram of prepared formulation were taken and keep into aluminium crucible with pierced aluminum lid and subjected to melting and crystallization at defined temperature from $25^{\circ} \mathrm{C}$ to $150^{\circ} \mathrm{C}$. The changes in entropy during melting were calculated using Eq. 1.

$$
\Delta \mathrm{G}=\Delta \mathrm{H}_{\mathrm{m}}-\mathrm{T}_{\mathrm{m}} \Delta \mathrm{S}
$$

Where, $\Delta G=$ Gibbs' free energy, $\Delta G$ is zero at the melting point of the material, though the enthalpy and the entropy of the sample increase.

The melting occurs at the point when DG of the liquid becomes lower than the solid. Electrical characterization is an important factor to quantify the different parameters of the bi-gel such as electrical conductance,

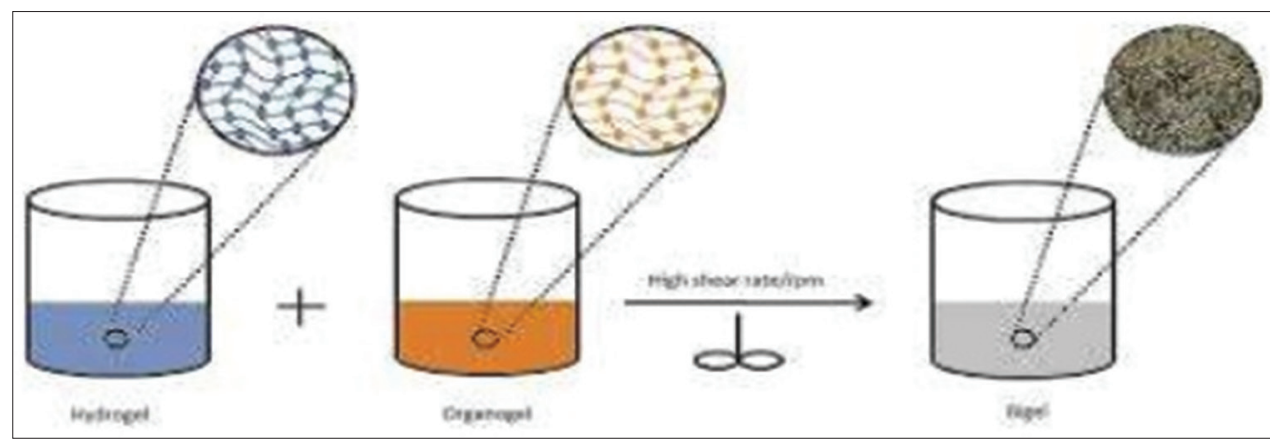

Fig. 3: Schematic diagram of preparation of bi-gel 
Table 1: Different bi-gel systems in the literature are reported for drug delivery applications

\begin{tabular}{|c|c|c|c|}
\hline Oil phase & Organogelator & Hydrogelator & Drug incorporated \\
\hline Corn oil & DIMODAN ${ }^{\circledR}$ monoglyceride & K-carrageenan & $\beta$-carotene $[1]$ \\
\hline Sweet almond oil & Span 65 & Alginate & Cetavlon $^{\circledR}[3]$ \\
\hline Sunflower oil & Sorbitan monopalmitate (Span 40) & $\begin{array}{l}\text { Guar gum, Acacia gum, } \\
\text { Xanthan gum }\end{array}$ & Metronidazole [35] \\
\hline Sunflower oil & Mixture of span 80 and tween 80 & Guar gum, Acacia gum & Metronidazole [36] \\
\hline Sunflower oil & Sorbitan monopalmitate (Span 40) & $\begin{array}{l}\text { Sodium alginate, Sodium } \\
\text { carboxy methyl cellulose, } \\
\text { Maltodextrin, Starch. }\end{array}$ & $\begin{array}{l}\text { Metronidazole. } \\
\text { L.Palatrum (Lp299v) [31] }\end{array}$ \\
\hline Sunflower oil & Sorbitan monopalmitate (Span 40) & $\begin{array}{l}\text { Polyvinylpyrrolidone } \\
\text { Poly (vinyl alcohol) }\end{array}$ & Metronidazole [28] \\
\hline Sunflower oil & Sorbitan monopalmitate (Span 40) & Gelatin, Whey protein & Metronodazole [37] \\
\hline Soyabean oil & $\begin{array}{l}\text { Sorbitan monosterate (Span 60), Cetyl } \\
\text { alcohol, Lecithin pluronic }\end{array}$ & $\begin{array}{l}\text { Hydroxypropylmethyl } \\
\text { cellulose }\end{array}$ & Diltiazem HCL [38] \\
\hline Fish oil & Beeswax & $\begin{array}{l}\text { Sodium alginate, Hydroxy } \\
\text { propyl methyl cellulose }\end{array}$ & Imiquimode [27] \\
\hline Sesame oil & Sorbitan monosterate (Span 60) & Gelatin & Ciprofloxacin [39] \\
\hline Sesame oil & Sorbitan monosterate (Span 60) & Guargum & Metronidazole [40] \\
\hline Sesame oil & Sorbitan monosterate (Span 60) & Carbopol & Metronidazole [27] \\
\hline Sesame oil & Sorbitan monosterate (Span 60) & Guargum & Ciprofloxacin [8] \\
\hline Soyabean oil & Steric acid & Mixture of agar and gelatin & Metronidazole [43] \\
\hline Rice bran oil & Stearly alcohol & Agarw & Ciprofloaxacin $\mathrm{HCl}[5]$ \\
\hline Fish oil & Bees wax & Carbopol & Imiquimod [41] \\
\hline Alomond oil & Sorbitan monosterate (Span 60) & Carbopol & Ketoprofen [44] \\
\hline Isopropyl palmitate & Mixture of soya lecithin and pluronic & $\begin{array}{l}\text { Hydroxy propyl methyl } \\
\text { cellulose }\end{array}$ & Flubiprofen $[45,46]$ \\
\hline $\begin{array}{l}\text { TegoSoft }^{\circledR} \text { CT } \\
\text { (Caprylic/capric triglycerides) }\end{array}$ & $\begin{array}{l}\text { Compritol }^{\circledR} \text { (Liquid excipient of } \\
\text { glycerylbehenate). }\end{array}$ & Carbopol & Ibuprofen [47] \\
\hline Rice bran oil & Steric acid & Tamarind gum & Moxifloxacin [48] \\
\hline Liquid paraffin & Polyethylene & Poloxamer 407 & $\begin{array}{l}\text { Ciclopirox olamine and } \\
\text { terbinafine } \mathrm{HCl} \text { [49] }\end{array}$ \\
\hline Oleogel & Polyethylene & Carbopol & NSAIDS [50] \\
\hline- & $\begin{array}{l}\text { Sorbitan monostearate }\left(\operatorname{Span}^{\circledR} 60\right) \text { and } \\
\text { polysorbate } 60\end{array}$ & Chitosan, HPMC & Tenofovir [51] \\
\hline
\end{tabular}

electrical resistance, and impedance, these parameter are directly associated with the efficacy of the controlled drug delivery. Electric conductance is key parameter for the phase inversion phenomenon during production, mixing, processing, and handling of multiphase systems [32-34]. Therefore, electric property of bi-gel analyzed by electrical conductivity analysis. The electric profile measured using computer-controlled impedance analyzer. The measured data within the range of $(0.1 \mathrm{~Hz}-1 \mathrm{MHz})$ at room temperature. It helps to understand the transport behavior under influence of current and microstructural arrangement of the system [9]. The 0/W shows conductivity behavior due to higher ions present in water phase, whereas $W / 0$ shows insulative behaviors approximately zero electric conductivity [33].

Rheological properties such as viscosity and swelling behavior of bigel are also important factors to be consider for the drug delivery. Higher viscosity system containing higher molecular weight-branched chain polymer and higher concentration of organogellator. Higher the concentration of hydrogel results to decreases the viscosity of the bi-gel system [35].

\section{APPLICATIONS}

In recent years, numerous bi-gel systems has been proposed particularly in the drug delivery. Most of these bi-gel systems are used as a carries for the controlled drug delivery of active ingredients for topical and transdermal application. Different bi-gel systems are reported in the literature for control drug delivery, as reported in Table 1.

\section{CONCLUSION}

In recent times, different bi-gel systems have been produced and modified according to the needs of different applications of drug delivery. This present review represents the importance of characteristics, different types of bi-gel system and its preparation, advantages of bi-gel system, and its application in drug delivery. Moreover, utilization of this system in pharmaceutical field has also been discussed.

\section{FUTURE PROSPECTIVE}

Bi-gels are emerging class of material, and therefore, extensive analysis of this system is required for commercial application. In this review, detailed discussion of different important parameters, such as storage of bi-gels and mixing speed, mixing temperature, addition of appropriate amount of organogelator and hydrogelator, and organogel/hydrogel ratio, are required for the preparation of bi-gel [52-57]. For future prospective, further investigation is required in this area to prepare a system with characteristic properties together with enhanced the drug delivery and release rate. Moreover, along with the pharmaceutical application, bi-gel system preparation is becoming a most emerging trend in the cosmetic and food applications.

\section{REFERENCES}

1. Zheng H, Mao L, Cui M, Liu J, Gao Y. Development of food-grade bi-gels based on $\kappa$-carrageenan hydrogel and monoglyceride oleogels as carriers for $\beta$-carotene: Roles of oleogel fraction. Food Hydrocolloid 2020;2020:105855.

2. Mukherjee S, Ash D, Majee SB, Biswas GR. Studies on span based soy bi-gels with HPMC. Res J Pharm Technol 2020;13:353-60.

3. Khelifi I, Saada M, Hayouni EA, Tourette A, Bouajila J, Ksouri R. Development and characterization of novel bi-gel-based 1 , 4-naphthoquinones for topical application with antioxidant potential. Arab J Sci Eng 2020;45:53-61.

4. Singh VK, Qureshi D, Nayak SK, Pal K. Bigels. In: Polymeric Gels. Vol. 1. Sawston: Wood Head Publishing; 2018. p. 265-82.

5. Kodela SP, Pandey PM, Nayak SK, Uvanesh K, Anis A, Pal K. Novel agar-stearyl alcohol oleogel-based bigels as structured delivery vehicles. Int J Polym Mater 2017;66:669-78. 
6. Behera B, Singh VK, Kulanthaivel S, Bhattacharya MK, Paramanik K, Banerjee I, et al. Physical and mechanical properties of sunflower oil and synthetic polymers based bigels for the delivery of nitroimidazole antibiotic-a therapeutic approach for controlled drug delivery. Eur Polym J 2015;64:253-64.

7. Lupi FR, Shakeel A, Greco V, Rossi CO, Baldino N, Gabriele D. A rheological and microstructural characterisation of bigels for cosmetic and pharmaceutical uses. Mater Sci Eng C 2016;69:358-65.

8. Singh V, Banerjee I, Agarwal T, Pramanik K, Bhattacharya MK, $\mathrm{Pal}$ K. Guar gum and sesame oil based novel bigels for controlled drug delivery. Colloid Surf B Biointerfaces 2014;123:582-92.

9. Lupi FR, Gentile L, Gabriele D, Mazzulla S, Baldino N, De Cindio B. Olive oil and hyperthermal water bigels for cosmetic uses. J Colloid Interf Sci 2015;459:70-8

10. Fekete T, Borsa J. Polysaccharide-based polymer gels. In: Polymer Gels, Gels Horizons: Sciences to Smart Materials. Vol. 1., Ch. 5. Singapore; Springer; 2018. p. 147-8.

11. Lin HR, Hsu CY, Lo YL. Preparation and characterization of dual phase transition oral hydrogel for sustained release of epirubicin. Int J Polym Biomater 2013;62:763-9.

12. Rehman K, Zulfakar MH. Recent advances in gel technologies for topical and transdermal drug delivery. Drug Dev Ind Pharm 2014;40:433-40.

13. Otto W, Drahoslav L. Hydrophilic gels in biologic use. Nature 1960;185:117-8.

14. Lupi FR, Shakeel A, Greco V, Baldino N, Calabro V, Gabriele D. Organogelation of extra virgin olive oil with fatty alcohols, glyceryl stearate and their mixture. LWT Food Sci Technol 2017;77:422-9.

15. Lupi FR, Gabriele D, Greco V, Baldino N, Seta L, De Cindio B. A rheological characterization of an olive oil/fatty alcohols organogel Food Res Int 2013;51:510-7.

16. Ogutcu M, Y1lmaz E. Characterization of hazelnut oil oleogels prepared with sunflower and carnauba waxes. Int J Food Prop 2015;18:1741-55.

17. Bollom MA, Clark S, Acevedo NC. Development and characterization of a novel soy lecithin-stearic acid and whey protein concentrate bigel system for potential edible applications. Food Hydrocolloids 2020;101:1055-70.

18. Schaink HM, Van Malssen KF, Morgado-Alves S, Kalnin D, Van der Linden E. Crystal network for edible oil organogels: Possibilities and limitations of the fatty acid and fatty alcohol systems. Food Res Int 2007;40:1185-93.

19. Kumar R, Katare OP. Lecithin organogels as a potential phospholipidstructured system for topical drug delivery: A review. AAPS PharmSciTech 2005;6:E298-310.

20. Dassanayake LS, Kodali DR, Ueno S, Sato K. Physical properties of rice bran wax in bulk and organogels. J Am Oil Chem Soc 2009;86:1163.

21. Sawalha H, Venema P, Bot A, Flöter E, van der Linden E. The influence of concentration and temperature on the formation of $\gamma$-oryzanol+ $\beta$-sitosterol tubules in edible oil organogels. Food Biophys 2011;6:20-5.

22. Mallia VA, George M, Blair DL, Weiss RG. Robust organogels from nitrogen-containing derivatives of (R)-12-hydroxystearic acid as gelators: Comparisons with gels from stearic acid derivatives. Langmuir 2009;25:8615-25

23. Suzuki M, Nanbu M, Yumoto M, Shirai H, Hanabusa K. Novel dumbbellform low-molecular-weight gelators based on L-lysine: Their hydrogelation and organogelation properties. New J Chem 2005;29:1439-44.

24. Shakeel A, Farooq U, Gabriele D, Marangoni AG, Lupi FR. Bigels and multi-component organogels: An overview from rheological perspective. Food Hydrocolloids 2020;10:1061-90.

25. Zhao W, Li Y, Sun T, Yan H, Hao A, Xin F, et al. Heat-set supramolecular organogels composed of $\beta$-cyclodextrin and substituted aniline in $\mathrm{N}$, N-dimethylformamide. Colloids Surf A Physicochem Eng Aspect 2011;374:115-20

26. Wassén S, Bordes R, Gebäck T, Bernin D, Schuster E, Lorén N, et al. Probe diffusion in phase-separated bicontinuous biopolymer gels. Soft Matter 2014;10:8276-87.

27. Yu G, Yan X, Han C, Huang F. Characterization of supramolecular gels. Chem Soc Rev 2013;42 6697-722.

28. Singh VK, Anis A, Banerjee I, Pramanik K, Bhattacharya MK, Pal K Preparation and characterization of novel carbopol based bigels for topical delivery of metronidazole for the treatment of bacterial vaginosis. Mater Sci Eng C 2014;44:151-8.

29. Rehman K, Amin MC, Zulfakar MH. Development and physical characterization of polymer-fish oil bigel (hydrogel/oleogel) system as a transdermal drug delivery vehicle. J Oleo Sci 2014:ess 14101.

30. Sreekumar M, Mathan S, Mathew SS, Dharan SS. Bigels: An updated review. J Pharm Sci Res 2020;12 1306-8.

31. Souza RL, Faria E, Figueiredo R, Fricks A. Use of polyethylene glycol in the process of sol-gel encapsulation of Burkholderia cepacia lipase. J Therm Anal Calorimetry 2014;117:301-6.

32. Pal R. Electromagnetic, Mechanical, and Transport Properties of Composite Materials. Boca Raton, Florid: CRC Press; 2014.

33. Singh VK, Sagiri SS, Pal K, Khade SM, Pradhan DK, Bhattacharya MK. Gelatin-carbohydrate phase-separated hydrogels as bioactive carriers in vaginal delivery: preparation and physical characterizations. J Appl Polym Sci 2014;131:40445.

34. Behera B, Sagiri SS, Singh VK, Pal K, Anis A. Mechanical properties and delivery of drug/probiotics from starch and non-starch based nove bigels: A comparative study. Starch-Stärke 2014;66:865-79.

35. Behera B, Dey S, Sharma V, Pal K. Rheological and viscoelastic properties of novel sunflower oil-span 40-biopolymer based bigels and their role as a functional material in the delivery of antimicrobial agents. Adv Polym Tech 2015;34:21488.

36. Sahoo S, Sing VK, Biswal D, Anis A, Rana UA, Al-Zahrani S, et al. Development of ionic and non-ionic natural gum-based bigels: Prospects for drug delivery application. J Appl Polym Sci 2015;132:42561.

37. Behera B, Sagiri SS, Pal K, Pramanik K, Rana UA, Shakir I, et al. Sunflower oil and protein-based novel bigels as matrices for drug delivery applications characterization and in vitro antimicrobia efficiency. Polym Plast Technol Eng 2015;54:837-50.

38. Ibrahim MM, Hafez SA, Mahdy MM. Organogels, hydrogels and bigels as transdermal delivery systems for diltiazem hydrochloride. Asian J Pharm Sci 2013;8:48-57.

39. Satapathy S, Singh VK, Sagiri SS, Agarwal T, Banerjee I, Bhattacharya MK, et al. Development and characterization of gelatinbased hydrogels, emulsion hydrogels, and bigels: A comparative study. J Appl Polym Sci 2015;132:41502.

40. Sagiri SS, Singh VK, Kulanthaivel S, Banerjee I, Basak P, Battachrya MK, et al. Stearate organogel-gelatin hydrogel based bigels: Physicochemical, thermal, mechanical characterizations and in vitro drug delivery applications. J Mech Behav Biomed Mater 2015;43:1-7.

41. Singh VK, Anis A, Al-Zahrani S, Pradhan DK, Pal K. Molecular and electrochemical impedance spectroscopic characterization of the carbopol based bigel and its application in iontophoretic delivery of antimicrobials. Int J Electrochem Sci 2014;9:5049-60.

42. Wakhet S, Singh VK, Sahoo S, Sagiri SS, Kulanthaivel S, Bhattacharya MK, et al. Characterization of gelatin-agar based phase separated hydrogel, emulgel and bigel: A comparative study. J Mater Sci Mater Med 2015;26:118.

43. Rehman K, Zulfakar MH. Novel fish oil-based bigel system for controlled drug delivery and its influence on immune modulatory activity of imiquimod against skin cancer. Pharm Res 2017;34:36-48.

44. Andonova VY, Peneva PT, Apostolova EG, Dimcheva TD, Peychev ZL, Kassarova MI. Carbopol hydrogel/sorbitan monostearatealmond oil based organogel biphasic formulations: Preparation and characterization of the bigels. Trop J Pharm Res 2017;16:1455-63.

45. Velichka A, Petya P, George SG, Vencislava TT. Ketoprofen loaded polymer carriers in bigel formulation: An approach to enhancing drug photostability in topical application forms. Int $\mathrm{J}$ Nanomed 2017; 12:6221-38

46. Charyulu RN, Muaralidharan A, Sandeep DS. Design and evaluation of bigels containing flurbiprofen. Res J Pharm Technol 2018;11:143-52.

47. Fang JY, Hwang TL, Fang CL. In vitro and in vivo evaluations of the efficacy and safety of skin permeation enhancers using flurbiprofen as a model drug. Int J Pharm 2003;255:153-66.

48. Hamed R, AbuRezeq AA, Tarawneh O. Development of hydrogels, oleogels, and bigels as local drug delivery systems for periodontitis. Drug Dev Ind Pharm 2018;44:1488-97.

49. Paul SR, Qureshi D, Yogalakshmi Y, Nayak SK, Singh VK, Syed I, et al. Development of bigels based on stearic acid-rice bran oil oleogels and tamarind gum hydrogels for controlled delivery applications. J Surf Deterg 2018;21:17-29.

50. Mazurkeviciute A, Ramanauskiene K, Ivaskiene M, Grigonis A, Briedis V. Topical antifungal bigels: Formulation, characterization and evaluation. Acta Pharm 2018;68:223-33.

51. Hamed R, Abu A, Tarawneh RO. Development of hydrogels, oleogels, and bigels as local drug delivery systems for periodontitis. Drug Dev Ind Pharm 2018;44:1488-97.

52. Martín-Illana A, Notario-Pérez F, Cazorla-Luna R, Ruiz-Caro R, Veiga MD. Smart freeze-dried bigels for the prevention of the sexual transmission of HIV by accelerating the vaginal release of tenofovir during intercourse. Pharmaceutics 2019;11:232.

53. Shakeel A, Lupi FR, Gabriele RD, Baldino N, De Cindio B. Bigels: A unique class of materials for drug delivery applications. Soft Mater 2018;16:77-93. 
54. Ahmad S, Francesca RL, Domenico G. Bigels: A unique class of materials for drug delivery applications. Soft Mater 2018;16:1-30.

55. Ahmad S, Ujala F, Tanveer I. Key characteristics and modelling of bigel systems: A review. Mater Sci Eng C 2019;19:932-53.
56. Shibayama M, Tanaka T. Phase transition and related phenomena of polymer gels. Adv Polym Sci 1993;1:1-62.

57. Sagiri SS, Behara B, Rafanan R. Organogels as matrices for controlled drug delivery: A review on the current state. Soft Mater 2014;12:47-72. 